Article

\title{
Assessing and Explaining the Efficiency of Extensive Olive Oil Farmers: The Case of Pelion Peninsula in Greece
}

\author{
Spyros Niavis ${ }^{1}$, Nikos Tamvakis ${ }^{2}$, Basil Manos ${ }^{3}$ and George Vlontzos ${ }^{2, *}$ (ID \\ 1 Department of Planning and Regional Development, University of Thessaly, Pedion Areos, \\ 38333 Volos, Greece; niavisspiros@gmail.com \\ 2 Department of Agriculture, Crop Production and Rural Development, University of Thessaly, \\ 38446 Volos, Greece; nitamvak@agr.uth.gr \\ 3 Department of Agriculture, Aristotle University of Thessaloniki, 54124 Thessaloniki, Greece; \\ manosb@agro.auth.gr \\ * Correspondence: gvlontzos@agr.uth.gr; Tel.: +30-242-109-3083
}

Received: 5 January 2018; Accepted: 11 February 2018; Published: 13 February 2018

\begin{abstract}
The production of olives and olive oil in the Mediterranean region is one of the most important cultivations. The continuous changes imposed by the European Common Agricultural Policy (CAP) towards strengthening the influence of market forces have increased the necessity for the assessment of the efficiency of production protocols or patterns being implemented by the farmers. As regards olive trees cultivation, the efficiency of inputs utilization has not been studied in depth, despite the fact that this is a critical issue for both farmers and consumers. This study evaluates the efficiency rates of 100 Greek agricultural holdings specialized on olive trees cultivation by implementing a Data Envelopment Analysis (DEA) input oriented model. The inputs being used are land, fertilizers, agrochemicals, labour, and energy. The output being used is the revenue of each holding. The results quantify the significant variations of efficiency scores, providing evidence that there is space for restructuring the production process, in order to improve efficiency and thus decrease the production cost of inefficient farmers.
\end{abstract}

Keywords: Data Envelopment Analysis; olives; efficiency; Greece; Mediterranean region

\section{Introduction}

The Mediterranean region has been the authentic place for olive trees cultivation and olive oil production since ancient times. The countries of the region in the 2016/17 season produced about 2.33 million tonnes of olive oils, accounting for more than $90 \%$ of total global output [1]. The product is highly exportable, as two thirds of the total oil production of the European Union (EU) Mediterranean countries is traded internationally [2]. The significance of the cultivation is furtherly proven via its influence on every tradition and religion of the region, which in fact extends its importance from the strict limits of dietary purposes. In addition, there is a series of studies verifying the positive impact of olive oil consumption on human health [2,3], which may explain the considerable increase of olive oil consumption globally [1]. This excessive demand is the driving force for cultivating olive trees and producing olive oil beyond the Mediterranean region, where the climate and soil conditions allow for it. There are many such successful cases in America, Asia, and Australia [1]. For Mediterranean farmers, this global recognition of the product can be regarded as an opportunity because of the widening of the potential market but also as a threat due to the excessive increase of produced quantities worldwide. The supply excess pushes producers' prices downward periodically, thus jeopardizing the sustainability of the production process [1]. According to Food and Agriculture Organization (FAO) of 
the United Nations (UN), the overall olive oil production for 2014 exceeds 3 million tones, with Spain the leading country, with $59 \%$ of the global production. Important global key players, regarding production, are Italy with $10 \%$, Greece with $7 \%$, Tunisia with $6 \%$, Morocco with $4.5 \%$, Turkey with $2.5 \%$, Syria with 3.5\%, Algeria with $1.8 \%$, and Portugal with 2.2\%. Outside the Mediterranean, the most important countries are Argentina and the USA, with their production though to remain still below $1 \%$ [4]. It is therefore quite important to introduce and apply methodology assessments capable and reliable for evaluating the efficiency level of cultivating and production practices.

On the policy level, the main target of the EU Common Agricultural Policy (CAP), especially after the implementation of the AGENDA 2000 reform, is to improve the operational efficiency of primary sectors of member states, aiming by this way to increase their sustainability in an environment where protectionism is substantially reduced or eliminated. Perhaps AGENDA 2000 can be characterised as the most radical reform, because it established a totally new framework for subsidies management, decoupled from both crop and animal production [5,6]. This new era of CAP started in 2005, providing by this way the ability of the EU to fully comply with the last World Trade Organization (WTO) agreement of the Uruguay Round [7].

This enforcement of influence of market forces on agricultural income formation increased the necessity for a continuous and more detailed assessment of production costs in agriculture, with this approach being one of the most feasible ways to increase the efficiency of the production processes. Up until now, not only for agriculture but for many economic sectors as well, the implementation of Data Envelopment Analysis (DEA) has contributed substantially towards this goal. The great strength of DEA is its simplicity and the absence of anya-priori assumptions regarding the production functional form and the error distribution. Moreover, the method exploits all available information regarding the issue under consideration and provides more comprehensive results for real life problems, since it allows the insertion of input and output variables of different measurement units [8-11]. Despite these strengths, DEA as a non-parametric method also comes up with limitations. The basic limitations regard the extraction of results that lack statistical properties and are affected by the sample size [12-15].

The rather high simplicity of the method has rendered it popular for applications in agricultural production and food processing industries, as well as in other important economic sectors, like banking, education, transport, and health care [11]. The method has not only been used to provide efficiency assessments at the enterprise level but also for informing policy makers who are continuously in need of new tools and aim, in many cases, to improve economic and environmental performance. The applicability of the methodology was based upon the fact that there is no need to have under consideration the prices of inputs and outputs, because the approach is non-parametric. The first implementation was applied to the paper industry in Sweden [15]. The same methodology was used for reallocation of emission permits for $15 \mathrm{EU}$ member states (as of 2003) regarding agricultural GHGs. The results verified that the reduction and reallocation mechanism applied was fair and thus benefitted countries operating up to or very close to the efficient frontier being obtained [16].

Taking into account the strengths of DEA in assessing the operational efficiency of farms, the present paper incorporates a DEA model in order to evaluate the efficiency of extensive olive oil farmers in the area of Pelion Peninsula in Greece. Targeting at a sample of 100 farmers, the paper classifies them according to their efficiency levels in using their available inputs towards the production of olives and further sheds light on the socioeconomic and demographic factors that may affect the efficiency levels of the farmers of the sample. The remainder of the paper is as follows. In the Background section the previous applications of DEA in the agricultural sector are analysed. Next, the Materials and Methods of the present paper are described. The Results section that follows presents the classification of farmers according to their efficiency and the statistical analysis results regarding the effect of various exogenous variables on the efficiency of farmers. The paper ends up with the conclusions in which some policy insights and proposals for further research are given. 


\section{Background}

DEA was introduced when Farrell (1957) stated the problem of measurement of productive efficiency [17]. Based on these ideas, Charnes et al. (1978) developed further this methodological approach quantifying relative deficiencies of multi-input and multi-output production units [18]. The most important characteristics of DEA are the use of peer groups, the identification of efficient operational practices, the setting of targets, the development of efficient strategies, the ability to monitor efficiency changes over time, and resource allocation [19]. The great acceptance and usefulness of DEA is proved by the use of it for efficiency assessment of very important production sectors of the economy, even nowadays [20]. One of the first implementations of this was for the banking sector $[18,21]$. Quite an important sector for economies is the energy one. Special research focus has been given on the electric power plants efficiency on both operational and environmental terms, with DEA being implemented for this purpose [22,23]. Additionally, DEA has been used for evaluation of logistics, and more specifically for ports efficiency evaluation, presenting by this way the best management practices in a highly competitive sector of international economy [24]. Using the same rationale, there were efficiency evaluations for school units and educational systems $[25,26]$ with satisfactory and widely acceptable results.

Agricultural production efficiency in various cases has been assessed with DEA models, proving the obvious impact of the methodology on primary sectors evaluation. A series of different inputs and outputs have been used in various combinations, covering by this way the natural, biological, economic, and environmental aspects of agricultural production [10]. The results being obtained have created a specific know-how on efficiency assessment by identifying the best mixture of both inputs and outputs, leading to efficiency measurements, as well as the impact and significance of these aspects on efficiency scores. DEA has been used for both animal and crop production assessments. The application of DEA to citrus production leads to specific alternatives to efficiency improvement, especially in areas where small size of agricultural holdings is a major issue, which is the case in many Mediterranean countries [27]. The most competitive animal production sector is the dairy one. In this case, two different DEA models have been applied that focus on natural and economic inputs and outputs. The results obtained verified that it is more important to combine in an efficient context both natural and economic resources than to focus on output maximization and, more specifically, milk maximisation [28]. Regarding the same trend, a similar study identified efficiency scores of different combinations of management practices and feeding [29,30]. A holistic approach in the same sector included in the analysis external operational parameters, as well as internal operational characteristics and micro-social issues used to assess efficiency. The results obtained focused on farm size and management, which can be either a constraint or a driving force [31].

The increasing significance of the environmental dimension of agricultural production has driven research towards assessing the impact of inputs being used in agriculture on eco-efficiency too. It has been proved that DEA methodology autonomously implemented to assess environmental efficiency is a widely accepted approach. This acceptance is based upon the accuracy of results for small data sets and the ability to include undesirable outputs and inputs [32]. For this reason, a combination of Life Cycle Assessment (LCA) and DEA has been used regarding evaluating agricultural production in both operational and environmental terms. LCA is a tool for estimating the possible environmental degradation when a process is being implemented or when a product is being produced. DEA implementation by using LCA results can lead to super efficiency analysis, which simplifies the selection process of reference performers, which an essential part of the benchmarking process [33]. The application of LCA and DEA for the dairy sector provided very useful and applicable results, and focused on reducing the operational cost of dairy farms, as well as improving their environmental footprint [34,35]. Quite vital issue for farming is the efficiency assessment of labour management too. Application of DEA to citrus cultivation leads to specific alternatives that focus on efficiency improvement in areas where small size of agricultural holdings is a major issue, which is the case in many Mediterranean countries [27]. 
Applications of DEA can be found also for mussel production, where the targets being obtained can be utilised as virtual cultivation sites with considerably less input use, achieving simultaneously more output production [36]. The fisheries sector is expanding quite fast, due to the continuous increase of demand for fishes and fish products. At the same time, the sector is being characterised by intense competitiveness and rivalry among firms, increasing the significance of efficiency. Interesting findings were found when DEA methodology was used to assess both operational and environmental efficiency. This combination was appropriate for these cases where multiple input/output data should be used, providing at the same time the ability of not using standard deviations, which is usually the case when working with average inventories [37]. The suitability of this methodology was verified for arable crops cultivation too. Iranian holdings producing soybeans were found to be efficient in up to $46 \%$ of the sample. The most important input contributors to global warming were irrigation and fertilization by $63 \%$ and $34 \%$, respectively, providing a road map for both efficiency improvement and mitigation of environmental degradation [38].

Following the same methodological approach, DEA was used to assess energy efficiency of wheat farms; it aimed to separate efficient from inefficient farmers on the basis of inputs being used in a wasteful way and quantify the gap among them. The most important findings, being at the same time quite impressive, originated that only $18 \%$ of growers were technically efficient, with the overall technical efficiency being 0.82 [39]. It has been also observed that by implementing energy optimisation methods, the total Greenhouse Gas (GHG) emissions can be reduced substantially [40]. The same methodology was applied for alfalfa production. In this, $46 \%$ of growers were found to be technically efficient, with an average technical efficiency of 0.84 . Optimisation of energy use improved the energy use efficiency by $10.6 \%$ [41]. DEA implementation for grape production and vinification verified quantified inefficiencies in both operational and environmental terms. In NW Spain, an average necessity of $30 \%$ in inputs reduction was identified, leading to an increase of $28-39 \%$ in environmental gains, depending on the impact category [42]. The same methodology was implemented for the assessment of energy efficiency of grape production. The main differences between efficient and inefficient farms were focused on the use of chemicals, diesel fuel, and water for irrigation. Education level is positively related to high efficiency scores [43].

Another quite important sector is the greenhouse production, which at the same time is quite competitive too. It is widely accepted that energy costs of greenhouse vegetable production are the most important ones, affecting directly feasibility and competitiveness of agricultural holdings. An input-output analysis quantified the energy efficiency of greenhouses producing vegetables, and more specifically, tomatoes and cucumbers. The results showed that inputs substantially affecting energy costs are diesel fuel and fertilizers. Quite important is also the energy ratio for the two cultivations, which is 0.69 and 1.48, respectively. In pure economic terms, it is indicated that tomato cultivation is more profitable than cucumber cultivation [44]. In a similar study, energy use efficiency in greenhouse was assessed by comparing again tomato and cucumber production; the results showed that there is a difference between them, with technical efficiency scores with an average of 0.94, signifying the increased competitiveness of the sector. Regarding energy efficiency, about $25.15 \%$ of the total input energy could be saved without reducing tomato yield [45]. In addition, the implementation of DEA for the determination of energy efficiency in greenhouse cucumber production, having included in this analysis the GHG emissions as an undesirable output, showed that $27 \%$ of the sample was efficient. In this study, $\mathrm{CO}_{2}$ emissions were included as the major GHG undesirable output [46]. However, the most intensive cultivation in greenhouses is floriculture. Rose production in greenhouses is a typical case of it, being at the same time absolutely necessary to keep efficiency rates quite high due to the high intensity of rivalry characterising the sector. Possible inefficiencies have a direct impact on competitiveness. Such an assessment demonstrated that, on average, technical efficiency up to 0.83 and input energy savings of about $43.59 \%$ could be achieved without reducing rose yield. This percentage can be considered as very important [47]. 
In addition, the DEA model when it was applied for policy efficiency measurement has proved to be a quite appropriate tool. When the issue was the assessment of regional inefficiencies for industry sectors, the calculation of efficiency scores of leading sectors, as an evaluation perspective of their future competiveness, proved to be a reliable methodology [48]. The same trend can be followed regarding development policies. It is accepted that public investments, mainly in infrastructure, aim to attract private investments. Efficiency assessment of such public policy was calculated by the use of DEA, identifying investment mixtures that attracted successfully private investments [49-52]. Finally, assessing rural development policies with DEA quantified the impact of them on employment generation in rural areas, and was, at the same time, a useful tool for reallocation of resources among different areas, thus maximising policy efficiency [53]. The same approach, when applied to the evaluation of local actions for LEADER+ project in Greece, identified inefficiencies regarding inputs use and proposed corrective alternatives that aimed to increase the total efficiency of this project [54].

Finally, as for the olive oil cultivation, there are several studies focusing on its efficiency assessment. The use of DEA for olive trees cultivation in Andalucía provided the ability to measure inefficiencies related to resources management like land and water, in a region where, especially, water availability is a crucial issue for both inhabitants and cultivations [55]. Spanish olive growers were proven to be quite eco-efficient, with inefficiencies that were closely related to technical inefficiencies. Eco-efficiency was boosted via implementation of agri-environmental projects like university education [56,57]. Eco-efficiency is closely related to land use management, too [58]. Finally, regarding the impact of CAP on farming efficiency, DEA application to olive-growing farms proposed an allocation system for subsidies, having in mind the new subsidy administrative scheme. Farm efficiencies were calculated by decomposing DEA scores by means of internalising both positive and negative externalities of agricultural activity [59]. Despite the existence of these useful findings, there is still a gap of new knowledge about both operational and environmental efficiency of other quite significant olive oil producing countries. The application of similar methodological approaches to different regions provides the researchers with comparable results, quantifying at the same time the possible differences that might occur, having always in mind the common policy framework being implemented in the EU.

\section{Material and Methods}

The scope of the present paper is the assessment of technical efficiency levels of extensive olive tree cultivation. This particular farming practice is quite important, because the olive oil being produced from such areas embodies unique aromatic and nutritional characteristics. The majority of these farms are rain fed and their productivity, in yield terms, is considerably lower compared with the modern intensive olive groves. Up to now there are now sufficient data and research findings to support such cases. The field research took place at Pelion Mountain situated in Magnesia Prefecture of Region of Thessaly, in Central Greece, during 2016 (Figure 1). The Region is inhabited by about 730 thousand people with the Gross Domestic Product (GDP) per capita hovering around $€ 14,700$ (in terms of Purchasing Power Parity) [60]. The region has a strong primary sector, as over $22 \%$ percent of the workforce is engaged in agricultural activities. Moreover, Mountain Pelion has about 20,000 inhabitants and its economy is mainly based on agriculture and tourism [61]. This specific region was chosen because it illustrates all the typical characteristics of such cases of extensive olive groves, being for this reason representative of similar cases in the Mediterranean. According to the Greek statistics agency in this area, there are 11,430 olive trees farms covering an acreage of approximately 20,000 Ha [62]. 

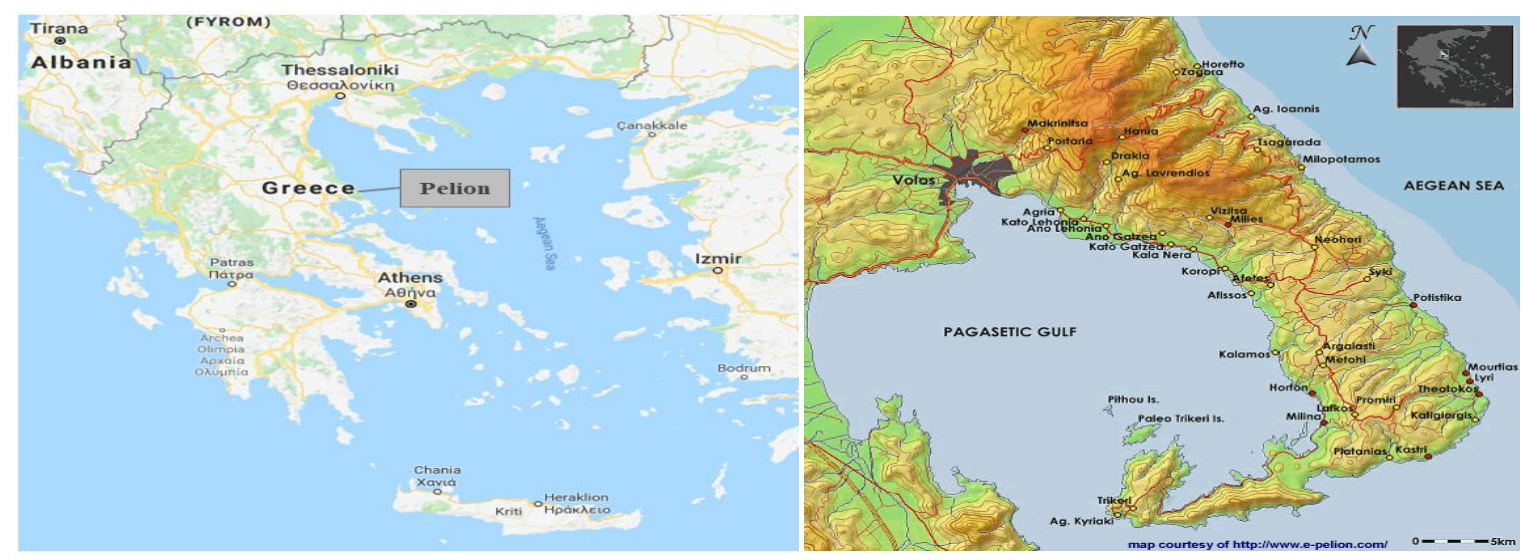

Figure 1. Field research placement.

In total, 100 farms participated in this research by reporting inputs usage, as well as the outputs being obtained. This sample was created following the stratified structure methodology, having as criteria the sex and age of farmers, as well as their farm size. The reference for this was the last national Census of Agricultural and Livestock Holdings. More specifically, the inputs being monitored were the acreage in Ha of each farm, and the annual costs of energy, agrochemicals, fertilizers, and labour, as outputs were considered the olive oil quantities produced from each farm and the revenue being achieved (Table 1). The above mixture of inputs and outputs follows the same methodological approach of similar studies already mentioned in the Background section, thus succeeding the comparability of the results obtained. The majority of farmers were male (up to $82 \%$ ), and the average age level was 56.4 years old. The classification of education level of the sample consists of $19 \%$ primary school, $14 \%$ high school, 32\% secondary school, and 35\% university graduates. The following table presents the descriptive statistics of both inputs and outputs being used for this research.

Table 1. Descriptive statistics of inputs and outputs.

\begin{tabular}{ccccc}
\hline & Mean & Standard Dev. & Min. & Max. \\
\hline Acreage $(\mathrm{Ha})$ & 28.17 & 47.53 & 5 & 400 \\
Fertilizers $(€)$ & 270.20 & 271.12 & 120 & 4000 \\
Fungicides $(€)$ & 41.90 & 133.33 & 110 & 2500 \\
Pesticides $(€)$ & 139.88 & 102.19 & 150 & 4500 \\
Labour $(€)$ & 2418 & 687.58 & 1200 & 120,000 \\
Energy $(€)$ & 574.25 & 344.81 & 60 & 11,000 \\
Yield $(\mathrm{Kg})$ & 1058.95 & 442.91 & 150 & 15,000 \\
Revenue $(€)$ & 3455.01 & 2410.34 & 1000 & 60,000 \\
\hline
\end{tabular}

Source: Own calculations.

Two critical decisions should be taken before applying a DEA model. The first regards the orientation of the model and whether the application of the DEA will seek to expand outputs or reduce inputs. The second regards the returns to scale of the production and whether these are assumed to be constant (Constant Returns to Scale-CRS model) or variable (Variable Returns to Scale_-VRS model). For the present study, the input-oriented VRS model will be selected to assess the efficiency of olive farms in Pelion region. VRS model comes up with better discriminatory power than the CRS model in a sense that can distinguish between pure technical efficiency (TE) and scale efficiency (SE), identifying if increasing, decreasing, or constant returns to scale are present [63]. The input oriented approach is more appropriate in this case, because the globalisation of both production and trade practices leads farmers to be cost efficient in order to achieve competitive advantage. Therefore, it is more useful for both farmers and policy makers to quantify the possible excess use of inputs, instead of considering as given the inputs being used during the production process. 
The following DEA model is estimated in order to measure the technical efficiency of the olive oil producing farms sample:

CRS Model

$$
\min \theta-\varepsilon\left(\sum_{i=1}^{n} S_{i}^{-}+\sum_{r=1}^{s} S_{r}^{+}\right)
$$

Subject to

$$
\begin{gathered}
\sum_{j=1}^{n} \lambda_{j} \chi_{i j}+S_{i}^{-}=\theta \chi_{i o} \quad i=1,2, \ldots, m \\
\sum_{j=1}^{n} \lambda_{j} y_{r j}-S_{r}^{+}=y_{r o} \quad r=1,2, \ldots, s \\
\lambda_{j} \geq 0 \quad j=1,2, \ldots, n
\end{gathered}
$$

VRS

$$
\text { Add } \sum_{j-1}^{n} \lambda_{j}=1
$$

in which $j$ is the number of observations of the Decision Making Units (DMU). Each observed $\mathrm{DMU}_{j}$ $(j=1,2, \ldots, n)$ uses $m$ inputs $x_{i j}(i=1,2, \ldots, m)$ to produce $s$ outputs $y_{r j}(r=1,2, \ldots, s)$. The efficient frontier is determined by these $n$ observations. There are two properties to ensure that a piecewise linear approximation has been developed to the efficient frontier and the area dominated by the frontier. $\sum_{j=1}^{n} \lambda_{j} \chi_{i j}(i=1,2, \ldots, m)$ and $\sum_{j=1}^{n} \lambda_{j} y_{r j}(r=1,2, \ldots, s)$ are feasible combinations of inputs and outputs for the $\mathrm{DMU}_{j}$, in which $\lambda_{j} \lambda(j=1,2, \ldots, n)$ are nonnegative scalars that $\sum_{j-1}^{n} \lambda_{j}=1$. The same $y_{r i} y$ can be obtained by using ${\hat{\chi_{i j}}}$, in which ${\hat{\chi_{i j}}} \geq \chi_{i j}$ and the same $x_{i j} x$ can be used to obtain $\hat{y}_{i j}$, in which $\hat{y}_{i j} \geq y_{i j} \cdot S_{i}^{-}$and $S_{j}^{+}$represent input and output slacks, respectively. The efficient targets are

$$
\begin{aligned}
\hat{\chi_{i j}} & =\theta^{*} \chi_{i o}-S_{i}^{-*} \quad i=1,2, \ldots, m \\
\hat{y_{i j}} & =y_{i o}+S_{i}^{+*} \quad r=1,2, \ldots, m
\end{aligned}
$$

If $\theta^{*}=1$, then the DMU under evaluation is a frontier point. If $\theta^{*}<1$, then the DMU under evaluation is inefficient and has to decrease its input levels. The non-zero optimal $\lambda_{j}^{*}$ represents the benchmarks for a specific DMU under evaluation.

\section{Results}

The findings of the implementation of the above model are being presented in the following tables (Tables 2 and 3 ).

Table 2. DEA VRS efficiency scores.

\begin{tabular}{cc}
\hline Descriptive Statistics & Values \\
\hline Average & 0.860 \\
Standard Deviation & 0.092 \\
Min & 0.576 \\
Max & 1.000 \\
\hline
\end{tabular}


Table 3. Efficiency classification of DMUs.

\begin{tabular}{cc}
\hline Efficiency Scores & No. of DMUs \\
\hline $0.50<$ Score $<0.59$ & 1 DMU \\
$0.60<$ Score $<0.69$ & 4 DMUs \\
$0.70<$ Score $<0.79$ & 18 DMUs \\
$0.80<$ Score $<0.89$ & 34 DMUs \\
$0.90<$ Score & 43 DMUs \\
\hline
\end{tabular}

The above findings provide useful information about the quantitative and qualitative characteristics of olive orchards farms. Despite the fact that the variance of the structural characteristics of farms is quite high, the efficiency results do not follow the same trend. Only $23 \%$ of the sample presented efficiency scores below 0.80 , while the $43 \%$ of the sample achieved efficiency scores between 0.9 and 1 . This classification can be considered as satisfactory, providing at the same time space for substantial improvements regarding cultivating practices. Comparing these findings with the ones obtained in similar studies, mainly in Spain [55], it is obvious that this specific type of farming succeeds to a large extent to remain competitive. Despite the fact that intensive olive trees groves achieve higher yields due to their structural characteristics, this study proves that, in efficiency terms, there are no significant differences, as would be expected. Given that quite important inputs are natural resources, this study provides primary evidence about the sustainable procedure of farming, in similar cases, of olive oil production.

Given the common production technology among the farmers, the efficiency variations could be attributed to several characteristics exogenous to the production function [64,65]. In order to define the effect of the exogenous factors on the efficiency of farmers, the scores obtained by the model 1 are regressed on selected demographic and socioeconomic characteristics of the farmers under consideration.

This variation of efficiency scores is quite important to be justified. One critical issue to be defined before conducting the regression analysis is the selection of its functional form. More precisely, the fact that efficiency scores obtained by DEA models are point estimates without statistical distribution renders the estimations of a parametric regression such as this of Ordinary Least Squares biased [66]. To overcome this difficulty, Simar and Wilson [67] proposed a truncated regression with parametric bootstrapping, which leads to more accurate and consistent results. Under the truncated regression, the distribution of the error term $\varepsilon_{j} \sim N\left(0, \sigma_{\varepsilon}^{2}\right)$ is assumed to be uniformly truncated with zero mean (before truncation) and unknown variance $\sigma_{\varepsilon}^{2}$. We specify the truncation limit at the maximum DEA score $(\theta=1)$ and obtain the parameters estimations using maximum likelihood procedure with 1000 bootstrap replications.

In total, five variables were selected to represent the exogenous factors of production. Two variables, namely Age are Land, are quantitative, whilst the variables Subsidies, Edu, and Sex have a dummy form. Table 4 presents the main descriptive statistics of the two continuous variables. As can be seen, the mean age of the farmers is 56 years, whilst values range from 21 to 90 years. It should be noted that $64 \%$ of the farmers are over 50 years old and $46 \%$ exceed 60 years. These figures denote that ageing is a dominant characteristic of local farmers. In addition, the mean land per farmer is estimated at $2.8 \mathrm{Ha}$. The variable presents quite high variability, as this is testified by the ratio of st. $d v$ to mean and by the large distance between the minimum value (1) and the maximum value (400). 
Table 4. Descriptive Statistics of the Continuous Exogenous Variables.

\begin{tabular}{ccc}
\hline Statistics & Age (Years) & Land (Ha) \\
\hline Mean & 56 & 2.8 \\
St.Dv. & 15 & 4.7 \\
Min & 21 & 0.1 \\
Max & 90 & 40.0 \\
\hline \multicolumn{3}{c}{ Source: Own calculations. }
\end{tabular}

As for the dummy variables, the variable Subsidies take the value of 1 when the total received subsidies per farmer exceeds $5000 €$ and 0 otherwise. The variable is used in order to test if increased subsidies are leading to more efficient farming practices. The threshold is set to 5000 , because this is the criterion for distinguishing the small farmers from the others. The variable $E d u$ receives a value of 1 if the farmer has completed university studies and 0 otherwise. The variable rather depicts the schooling years of the respondents and not their specialization in agricultural studies. Although the latter could lead to more accurate and rational estimations, the former was finally inserted to the model, because only a minor proportion of the respondents have attained agricultural studies. In addition, it should be noted that variables depicting the schooling years of farmers have also been used in a wide range of similar studies [56,64]. Finally, the variable Sex receives the value of 1 for male farmers and 0 for female farmers. The variable has been inserted in order to capture any efficiency variations between the production practices of men and women. Having defined the variables, the regression analysis is performed by solving the Model (5):

$$
\begin{gathered}
E f f_{i}=\beta_{o}+\beta_{1} \text { Age }_{i}+\beta_{2} \text { Land }_{i}+\beta_{3} \text { Subsidies }_{i}+\beta_{4} E d u_{i} \\
+\beta_{5} \operatorname{Sex}_{i} \quad(i=1,2, \ldots, 100)
\end{gathered}
$$

In which,

Eff $=$ Efficiency Scores $\theta$ extracted by Models (1) and (2)

Age, Land $=$ The Continuous Independent Variables

Subsidies, Edu, Sex = The Dummy Independent Variables

$\beta_{0}=$ The Constant Term

$\beta_{j}=$ The Regression Coefficients Under Estimation $(j=1, \ldots, 5)$

For comparative reasons, both the estimations extracted by a simple truncated regression and those extracted by the bootstrapped regression are presented in Table 5. The value of the Wald Chi-Square statistic and the statistical significance of the estimation for both models denote that we can reject the null hypothesis that all the parameters are equal to zero. As far as the estimated coefficients of the models are concerned, these are similar in both models in terms of the direction between the regressors, the dependent variable, and the statistical significance of estimations. The only difference is the lowest statistical significance for the estimation of $\beta_{\text {Subsidies }}$ that was found under the bootstrapped model. In general, statistical significance was found for the $\beta_{\text {Land }}, \beta_{0}$, and $\beta_{\text {Sex }}$ coefficients, whereas for the other two variables the model application returned ambiguous estimations.

The Land variable was found to be negatively connected to the farmers' efficiency, meaning that farmers with larger cultivation areas seem to be less effective than those with smaller areas. In addition, the positive estimation for Subsidies coefficient denotes that as subsidies increase the farmers become more efficient. Moreover, the positive sign of the $\beta_{S e x}$ estimation signifies that for the considered farmers' sample, men tend to employ more efficient production means than women. Finally, farmers' age seems to be positively connected to their efficiency, whereas the opposite stands for their education level. Nevertheless, since both estimations lack statistical significance, no safe conclusions could be drawn for their relationship with the efficiency of farmers. 
Table 5. Results of the Truncated Regression Model Application.

\begin{tabular}{|c|c|c|c|c|}
\hline \multirow[b]{2}{*}{ Parameter } & \multicolumn{2}{|c|}{ Truncated Regression } & \multicolumn{2}{|c|}{ Bootstrapped Truncated Regression } \\
\hline & Estimation & Std. Err. & Estimation & Std. Err. \\
\hline$\beta_{\text {Age }}$ & 0.0001 & 0.0003 & 0.0001 & 0.0003 \\
\hline$\beta_{\text {Land }}$ & $-0.0033^{* * *}$ & 0.0002 & $-0.0033^{* * *}$ & 0.0005 \\
\hline$\beta_{\text {Subsidies }}$ & $0.1004^{* * *}$ & 0.0298 & $0.1004 *$ & 0.0590 \\
\hline$\beta_{E d u}$ & -0.0023 & 0.0106 & -0.0023 & 0.0005 \\
\hline$\beta_{\text {Sex }}$ & $0.0263 * *$ & 0.0127 & $0.0263 * *$ & 0.0121 \\
\hline$\beta_{0}$ & $0.9042 * * *$ & 0.0228 & $0.9042 * * *$ & 0.0271 \\
\hline$\sigma$ & 0.0473 & 0.0038 & 0.0473 & 0.0037 \\
\hline Loglikelihood & \multicolumn{2}{|c|}{161.441} & \multicolumn{2}{|c|}{161.441} \\
\hline Wald chi2 (5) & \multicolumn{2}{|c|}{251.800} & \multicolumn{2}{|c|}{71.630} \\
\hline Prob > chi2 & \multicolumn{2}{|c|}{0.000} & \multicolumn{2}{|c|}{0.000} \\
\hline
\end{tabular}

Source: Own Estimations. Statistical significance: $\left({ }^{* * *}\right)$ at 0.01 level; $\left({ }^{* *}\right)$ at 0.05 level; $\left({ }^{*}\right)$ at 0.10 level.

\section{Conclusions}

From the above analyses, it is obvious that there is considerable potential for efficiency improvement regarding olive orchards' cultivation. The representative characteristics of the sample signify the most important parameters that needed to be changed in order to increase efficiency. These parameters are a better utilization of the subsidies that are being received. Quite important is the fact that the Land factor is negatively related to the efficiency scores. This outcome reflects the impact of the previous subsidy scheme, before the implementation of Agenda 2000, in which the amount of subsidies received was coupled with the olive oil quantities being produced by the farmers. After the total decoupling of subsidies from production, these amounts are stagnated even if the acreage of holdings is bigger.

It is evident that even though the subsidy administration scheme changed 12 years ago, the spillover effect of the previous status is still present. It is quite important that efficiency levels are obtained, bearing in mind the structural deficiencies of such groves, like the low density of trees, high slopes, the low availability of irrigation, and the low mechanization level of farming. Therefore, there is a need for training, especially for women, that has as a target the adoption of new knowledge about cultivation practices and aims to bridge the gap between the two sexes. The results of this study can be characterized as primary, setting by this way their limitations. There is a need for applying the same methodology, by using as a sample a mixture of extensive and intensive olive trees farms, in order to assess their efficiency levels and classify the importance of the factors being used in the second stage regression analysis. There is a need also to apply the same research approach on an international level, in order to quantify possible differences in efficiency levels globally. Finally, as for the Greek case, future efficiency estimations should also incorporate the environmental dimension of oil cultivation.

Acknowledgments: The authors would like to acknowledge the anonymous reviewers who provided useful comments before this manuscript was submitted to Agriculture journal.

Author Contributions: Nikos Tamvakis contributed in the data selection, Spyros Niavis performed the computations and George Vlontzos in cooperation with Basil Manos conceived of the presented idea. All authors discussed the results and contributed to the final manuscript.

Conflicts of Interest: The authors Spyros Niavis, Nikos Tamvakis, Basil Manos and George Vlontzos certify that they have NO affiliations with or involvement in any organization or entity with any financial interest (such as honoraria; educational grants; participation in speakers' bureaus; membership, employment, consultancies, stock ownership, or other equity interest; and expert testimony or patent-licensing arrangements), or non-financial interest (such as personal or professional relationships, affiliations, knowledge or beliefs) in the subject matter or materials discussed in this manuscript. 


\section{References}

1. International Olive Council. World Olive Oil Figures. Available online: http://www.internationaloliveoil. org/estaticos/view /131-world-olive-oil-figures (accessed on 2 February 2018).

2. European Commission. Economic Analysis of the Olive Sector. Available online: https://ec.europa.eu/ agriculture/olive-oil/economic-analysis_en.pdf (accessed on 4 February 2018).

3. Uylaşer, V.; Yildiz, G. The historical development and nutritional importance of olive and olive oil constituted an important part of the Mediterranean diet. Crit. Rev. Food Sci. 2014, 54, 1092-1101. [CrossRef] [PubMed]

4. FAOSTAT. Factsheet, S. Greece. Available online: http://www.fao.org/faostat/en/\#data/QC (accessed on 29 July 2017).

5. Manos, B.; Bournaris, T.; Chatzinikolaou, P. Impact assessment of CAP policies on social sustainability in rural areas: An application in Northern Greece. Oper. Res. 2011, 11, 77-92. [CrossRef]

6. Manos, B.; Bournaris, T.; Chatzinikolaou, P.; Berbel, J.; Nikolov, D. Effects of CAP policy on farm household behaviour and social sustainability. Land Use Policy 2013, 31, 166-181. [CrossRef]

7. European Commission. Policy Perspectives for EU Agriculture. Available online: http://ec.europa.eu/ agriculture/policy-perspectives/index_en.htm (accessed on 19 May 2016).

8. Emrouznejad, A.; Parker, B.R.; Tavares, G. Evaluation of research in efficiency and productivity: A survey and analysis of the first 30 years of scholarly literature in DEA. Socioecon. Plan. Sci. 2008, 42, 151-157. [CrossRef]

9. Mulwa, R.; Emrouznejad, A.; Muhammad, L. 'Economic efficiency of smallholder maize producers in Western Kenya: A DEA meta-frontier analysis'. Int. J. Oper. Res. 2009, 4, 250-267. [CrossRef]

10. Vlontzos, G.; Pardalos, P.M. Assess and Prognosticate Operational and Environmental Efficiency of Primary Sectors of EU Countries. In Driving Agribusiness with Technology Innovations, 1st ed.; IGI Global: Hashley, PA, USA, 2017; pp. 1-19. ISBN 9781522521075.

11. Vlontzos, G.; Pardalos, P.M. Assess and prognosticate greenhouse gas emissions from agricultural production of EU countries, by implementing, DEA Window analysis and artificial neural networks. Renew. Sustain. Energy Rev. 2017, 76, 155-162. [CrossRef]

12. De Witte, K.; Marques, R.C. Influential observations in frontier models, a robust non-oriented approach to the water sector. Ann. Oper. Res. 2010, 181, 377-392. [CrossRef]

13. Sharma, K.R.; Pingsun, L.; Zaleski, H.M. Productive efficiency of the swine industry in Hawaii: Stochastic frontier vs. data envelopment analysis. J. Prod. Anal. 1997, 8, 447-459. [CrossRef]

14. Vlontzos, G.; Niavis, S. Assessing the Evolution of Technical Efficiency of Agriculture in EU Countries: Is There a Role for the Agenda 2000? In Agricultural Cooperative Management and Policy. Cooperative Management; Zopounidis, C., Kalogeras, N., Mattas, K., van Dijk, G., Baourakis, G., Eds.; Springer: Cham, Germany, 2014; pp. 339-351. ISBN 978-3-319-06634-9.

15. Lozano, S.; Villa, G.; Brannlund, R. Centralized reallocation of emission permits using DEA. Eur. J. Oper. Res. 2009, 193, 752-760. [CrossRef]

16. Wu, H.; Du, S.; Liang, L.; Zhou, Y. DEA-based approach for fair reduction and reallocation of emission permits. Math. Comput. Model. 2013, 58, 1095-1101. [CrossRef]

17. Farrell, M.J. The measurement of productive efficiency. J. R. Stat. Soc. 1957, 120, 253-281. [CrossRef]

18. Charnes, A.; Cooper, W.W.; Rhodes, E.L. Measuring the efficiency of decision making units. Eur. J. Oper. Res. 1978, 2, 429-444. [CrossRef]

19. Boussofiane, A.; Dyson, R.G.; Thanassoulis, E. Applied data envelopment analysis. Eur. J. Oper. Res. 1991, 52, 1-15. [CrossRef]

20. Cook, W.; Seiford, L. Data envelopment analysis (DEA)-Thirty years on. Eur. J. Oper. Res. 2009, $19,1-17$. [CrossRef]

21. Thanassoulis, E. Data Envelopment Analysis and Its Use in Banking. Interfaces 1999, 29, 1-13. [CrossRef]

22. Sozen, A.; Alp, I.; Ozdemir, A. Assessment of operational and environmental performance of the thermal power plants in Turkey by using data envelopment analysis. Energy Policy 2010, 3, 6194-6203. [CrossRef]

23. Arabi, B.; Munisamy, S.; Emrouznejad, A.; Shadman, F. Power industry restructuring and eco-efficiency changes: A new slacks-based model in Malmquist-LuenbergerIndex measurement. Energy Policy 2014, 68, 132-145. [CrossRef] 
24. Cullinane, K.; Wang, T.F.; Song, D.W.; Ji, P. The technical efficiency of container ports: Comparing data envelopment analysis and stochastic frontier analysis. Transp. Res. Part A Policy Pract. 2006, 40, 354-374. [CrossRef]

25. Smith, P.; Mayston, D.J. Measuring efficiency in the public sector. Omega 1987, 15, 181-189. [CrossRef]

26. Thanassoulis, E.; Dunstan, P. Guiding schools to improved performance using data envelopment analysis: An illustration with data from a local education authority. J. Oper. Res. Soc. 1994, 45, 1247-1262. [CrossRef]

27. Martinez, E.R.; Picazo-Tadeo, A.J. Analysing farming systems with Data Envelopment Analysis: Citrus farming in Spain. Agric. Syst. 2004, 82, 17-30. [CrossRef]

28. Stokes, J.R.; Tozer, P.R.; Hyde, J. Identifying Efficient Dairy Producers Using Data Envelopment Analysis. J. Diary Sci. 2007, 90, 2555-2562. [CrossRef] [PubMed]

29. Heinrichs, A.J.; Jones, C.M.; Gray, S.M.; Heinrichs, P.A.; Cornelisse, S.A.; Goodling, R.C. Identifying efficient dairy heifer producers using production costs and data envelopment analysis. J. Diary Sci. 2013, 90, 7355-7362. [CrossRef] [PubMed]

30. Hansson, H.; Ohlmer, B. The effect of operational managerial practices on economic, technical and allocative efficiency at Swedish dairy farms. Livest. Sci. 2008, 11, 34-43. [CrossRef]

31. Hansson, H. Strategy factors as drivers and restraints on dairy farm performance: Evidence from Sweden. Agric. Syst. 2007, 94, 726-737. [CrossRef]

32. Song, M.; An, Q.; Zhang, W.; Wang, Z.; Wu, J. Environmental efficiency evaluation based on data envelopment analysis: A review. Renew. Sustain. Energy Rev. 2012, 16, 4465-4469. [CrossRef]

33. Iribarren, D.; Hospido, A.; Moreira, M.T.; Feijoo, G. Benchmarking environmental and operational parameters through eco-efficiency criteria for dairy farms. Sci. Total Environ. 2011, 409, 1786-1798. [CrossRef] [PubMed]

34. Silva, E.; Stefanou, S.E. Nonparametric Dynamic Production Analysis and the Theory of Cost. J. Prod. Anal. 2003, 19, 5-32. [CrossRef]

35. Iribarren, D.; Vasquez-Rowe, I.; Moreira, M.T.; Feijoo, G. Further potentials in the joint implementation of life cycle assessment and data envelopment analysis. Sci. Total Environ. 2010, 408, 5265-5272. [CrossRef] [PubMed]

36. Lozano, S.; Iribarren, D.; Moreira, M.T.; Feijoo, G. The link between operational efficiency environmental impacts. A joint application of Life Cycle Assessment and Data Envelopment. Sci. Total Environ. 2009, 407, 1744-1754. [CrossRef] [PubMed]

37. Vasquez-Rowe, I.; Iribarren, D. Review of Life-Cycle Approaches Coupled with Data Envelopment Analysis: Launching the CFP + DEA Method for Energy Policy Making. Sci. World J. 2015, 2015, 1-10. [CrossRef] [PubMed]

38. Mohammadi, A.; Shahin, R.; Jafari, A.; Dalgaard, T.; Trydeman Knudsen, M.; Keyhani, A.; Mousavi-Avval, S.H.; Hermansen, J.E. Potential greenhouse gas emission reductions in soybean farming: A combined use of Life Cycle Assessment and Data Envelopment Analysis. J. Clean Prod. 2013, 54, 89-100. [CrossRef]

39. Khoshnevisan, B.; Rafiee, S.; Omid, M.; Mousazadeh, H. Applying data envelopment analysis approach to improve energy efficiency and reduce GHG (greenhouse gas) emission of wheat production. Energy 2013, 58, 588-593. [CrossRef]

40. Khoshnevisan, B.; Rafiee, S.; Omid, M.; Yousefi, M. Modeling of energy consumption and GHG (greenhouse gas) emissions in wheat production in Esfahan province of Iran using artificial neural networks. Energy 2013, 52, 333-338. [CrossRef]

41. GhasemiMobtaker, H.; Akram, A.; Keyhani, A.; Mohammadi, A. Optimization of energy required for alfalfa production using data envelopment analysis approach. Energy Sustain. Dev. 2012, 16, 242-248. [CrossRef]

42. Vasquez-Rowe, I.; Villanueva-Rey, P.; Iribarren, D.; Moreira, M.T.; Feijoo, G. Joint life cycle assessment and data envelopment analysis of grape production for vinification in the RiasBaixas appellation (NW Spain). J. Clean Prod. 2012, 27, 92-102. [CrossRef]

43. Khoshroo, A.; Mulwa, R.; Emrouznejad, A.; Arabi, B. A non-parametric Data Envelopment Analysis approach for improving energy efficiency of grape production. Energy 2013, 63, 189-194. [CrossRef]

44. Heidari, M.D.; Omid, M. Energy use patterns and econometric models of major greenhouse vegetable productions in Iran. Energy 2011, 36, 220-225. [CrossRef]

45. Pahlavan, R.; Omid, M.; Akram, A. Energy use efficiency in greenhouse tomato production in Iran. Energy 2011, 36, 6714-6719. [CrossRef] 
46. Khoshnevisan, B.; Rafiee, S.; Omid, M.; Mousazadeh, H. Reduction of $\mathrm{CO}_{2}$ emission by improving energy use efficiency of greenhouse cucumber production using DEA approach. Energy 2013, 55, 676-682. [CrossRef]

47. Pahlavan, R.; Omid, M.; Rafiee, S.; Mousavi-Avval, S.H. Optimization of energy consumption for rose production in Iran. Energy Sustain. Dev. 2012, 16, 236-241. [CrossRef]

48. Dine, M.; Haynes, K.E. Sources of regional inefficiency. An integrated shift-share, data envelopment analysis and input-output approach. Ann. Reg. Sci. 1999, 33, 469-489.

49. Karkazis, J.; Thanassoulis, E. Assessing the Effectiveness of Regional Development Policies in Northern Greece Using Data Envelopment Analysis. Socioecon. Plann. Sci. 1998, 32, 123-137. [CrossRef]

50. Abello, J.; Pardalos, P.M.; Resende, M. Handbook of Massive Data Sets; Kluwer Academic Publishers: Norwell, MA, USA, 2002; ISBN 1402004893.

51. Papajorgji, P.J. Pardalos, P.M. Software Engineering Techniques Applied to Agricultural Systems: An Object-Oriented and UML Approach; Springer US: New York, NY, USA, 2006; ISBN 9781441939265.

52. Zopounidis, C.; Pardalos, P.M. Handbook of Multicriteria Analysis; Springer: Berlin/Heidelberg, Germany, 2010; ISBN 9783540928270.

53. Vennesland, B. Measuring rural economic development in Norway using data envelopment analysis. For. Policy Econ. 2005, 7, 109-119. [CrossRef]

54. Vlontzos, G.; Arabatzis, G.; Manos, B. Investigation of the relative efficiency of LEADER+ in rural areas of Northern Greece. Int. J. Green Econ. 2014, 8, 37-48. [CrossRef]

55. Gomez-Limon, J.A.; Picazo-Tadeo, A.J.; Reig-Martinez, E. Eco-efficiency assessment of olive farms in Andalusia. Land Use Policy 2012, 29, 395-406. [CrossRef]

56. Picazo-Tadeo, A.; Gomez-Limon, J.A.; Martinez, E.R. Assessing farming eco-efficiency: A Data Envelopment Analysis approach. J. Environ. Manag. 2011, 92, 1154-1164. [CrossRef] [PubMed]

57. Picazo-Tadeo, A.; Beltran-Esteve, M.; Gomez-Limon, J.A. Assessing eco-efficiency with directional distance functions. Eur. J. Oper. Res. 2012, 220, 298-309. [CrossRef]

58. Kuosmanen, T.; Kortelainen, M. Measuring Eco-efficiency of Production with Data Envelopment Analysis. J. Ind. Ecol. 2005, 9, 59-72. [CrossRef]

59. Amores, A.; Contreras, I. New approach for the assignment of new European agricultural subsidies using scores from data envelopment analysis: Application to olive-growing farms in Andalusia (Spain). Eur. J. Oper. Res. 2009, 193, 718-729. [CrossRef]

60. European Commission. Region of Thessalia. Available online: https://ec.europa.eu/growth/toolsdatabases/regional-innovation-monitor/base-profile/region-thessalia (accessed on 3 February 2018).

61. Hellenic Statistical Authority. Interactive Map. Available online: http://www.statistics.gr/en/interactivemap (accessed on 1 February 2018).

62. Hellenic Statistical Authority. Distribution of Utilised Agricultural Area, by Type of Use, Region and Department. Available online: http:/ / www.statistics.gr/en/statistics/-/ publication/SPG31 (accessed on 3 February 2018).

63. Banker, R.D.; Charnes, A.; Cooper, W.W. Some Models for Estimating Technical and Scale Efficiencies in Data Envelopment Analysis. Manag. Sci. 1984, 30, 1078-1092. [CrossRef]

64. Battese, G.E.; Coelli, T.J. A model for technical inefficiency effects in a stochastic frontier production function for panel data. Empir. Econ. 1995, 20, 325-332. [CrossRef]

65. Simões, P.; Marques, R. On the economic performance of the waste sector. A literature review. J. Environ. Manag. 2012, 106, 40-47. [CrossRef]

66. Niavis, S.; Tsekeris, T. Ranking and causes of inefficiency of container seaports in South-Eastern Europe. Eur. Transp. Res. Rev. 2012, 4, 235-244. [CrossRef]

67. Simar, L.; Wilson, P.W. Estimation and inference in two-stage, semi-parametric models of production processes. J. Econ. 2007, 136, 31-64. [CrossRef]

(C) 2018 by the authors. Licensee MDPI, Basel, Switzerland. This article is an open access article distributed under the terms and conditions of the Creative Commons Attribution (CC BY) license (http:/ / creativecommons.org/licenses/by/4.0/). 